\title{
Life Expectancy Varies in Local Communities in Chicago: Racial and Spatial Disparities and Correlates
}

\author{
Bijou R. Hunt • Gary Tran • Steven Whitman
}

Received: 20 October 2014 / Revised: 30 January 2015 / Accepted: 16 February 2015 /Published online: 24 March 2015

(C) W. Montague Cobb-NMA Health Institute 2015

\begin{abstract}
Objectives Life expectancy in the USA reached a record high of 78.7 years in 2010 . However, the racial gap in life expectancy persists. National data, which are readily available, provide averages which mask important local-level differences. Local data are needed to identify the worst off groups, key to reducing disparities and pursuing health equity.

Methods Using vital records data, we calculated life expectancy for the USA and Chicago by race/ethnicity and gender and for Chicago's 77 community areas. We also examined the correlation between life expectancy and (1) racial/ethnic composition of a community area and (2) median household income. Results In Chicago, the highest life expectancy was observed among Hispanics at 84.6 and the lowest life expectancy was observed among Blacks at 71.7-a difference of about 13 years. Life expectancy varied substantially across the 77 community areas of Chicago, from a low of 68.2 to a high of 83.3 - a difference of 15 years. There were strong correlations between life expectancy and the racial, ethnic, and socioeconomic distributions among the community areas.

Conclusions The examination of data at the local level provides invaluable insight into which communities are facing the greatest burden in terms of health and well-being. It is only through the examination of local-level data that we can understand the unique needs of these communities and begin to address them.
\end{abstract}

Steven Whitman passed away during the preparation of this study.

B. R. Hunt $(\bowtie) \cdot$ S. Whitman

Sinai Urban Health Institute, Mount Sinai Hospital, Sinai Health

System, 1500 S. California Ave., Room K443, Chicago, IL 60608,

USA

e-mail: bijou.hunt@sinai.org

G. Tran

Chicago Medical School, Rosalind Franklin University, North

Chicago, IL, USA
Keywords Health disparities $\cdot$ Race $\cdot$ Black $\cdot$ Hispanic $\cdot$ Life expectancy $\cdot$ Socioeconomic status

Public health, technological, and scientific advances have led to better health and longevity in all parts of the world, including the USA. Over time, this has resulted in longer life expectancy, a prominent measure of a population's health. For example, from 1980 to 2010, the US life expectancy increased from 70.0 to 76.2 years for males and from 77.4 to 81.0 years for females [1]. Despite this notable progress, race continues to be a significant predictor of life expectancy. In 2010, the life expectancies for non-Hispanic Whites (Whites), non-Hispanic Blacks (Blacks), and Hispanics were 78.8, 74.7, and 81.2 years, respectively [1]. In addition to race/ethnicity [2, $3]$, several other factors that influence life expectancy have been identified, such as age [4], gender [5], education [6,7], income [8,9], and other social determinants of health [10-14].

National- and state-level life expectancy data are abundant and provide substantial information and assessment of the current population's health [15-17]. However, there is limited research using more local data [8, 18-22]. These types of analyses can be especially useful in providing further insight into smaller areas by revealing variations concealed by the averages of large population data. In addition, information gleaned from these analyses can spur local policy changes and guide appropriate resource allocation [23]. Identification of the worst off groups is the key to reducing disparities and pursuing health equity.

With this in mind, we analyzed vital statistics data for Chicago and its 77 community areas and calculated the life expectancy for each. We also examined life expectancy by race/ethnicity and gender and compared these estimates to national life expectancy data. Finally, we examined the correlations between life expectancy and (a) racial/ethnic composition of a community area and (b) median household income. 
Chicago provides a good setting for such a study as it is one of the most segregated cities in the USA [24], and racial disparities in several health outcomes have been well documented at both the city and community levels [25-29].

\section{Methods}

Setting Chicago is the third largest city in the United States, with 2,700,000 residents. The racial/ethnic make-up of Chicago in 2010 was $29 \%$ Hispanic, $32 \%$ Black, and $32 \%$ White. In 2008, there were just under 20,000 deaths in the city [30]. Chicago is divided into 77 officially designated community areas which are the sums of census tracts and which have historically been used to examine local variations in health data.

Measures Life expectancy was calculated by employing the Chiang methodology to construct current life tables [31]. Current life tables project the life span of each individual in a hypothetical cohort using the actual death rates of a given population. To estimate the life expectancy by age (19 age groups: $0,1-4,5-9,10-14, \ldots 80-84$, and $85+$ ), race/ethnicity (White, Black, and Hispanic), and sex for Chicago and US residents, three data elements were required: the number of births, the number of deaths in each age group, and the population in each age group. Given past research which has shown that the census counts for the zero age group are often inaccurate [32], we used births to estimate the population of age group zero.

To calculate the number of births and deaths, we analyzed birth and death certificates from Illinois Vital Records supplied to us by the Chicago Department of Public Health for all residents of the city of Chicago during the years 2006, 2007, and 2008 (2008 being the most recent year for which data were available) [30,33]. Data for denominators were drawn from the US Census Bureau, 2000 and 2010 as the annual population estimates available for 2006, 2007, and 2008 do not provide the level of detail necessary for the construction of a life table. Using data from these two points, we performed linear interpolation, which assumes a constant rate of population change, to obtain the denominators for 2006, 2007, and 2008. We used data from these years to calculate a three-year average life expectancy.

For purposes of comparison, we present life expectancy at the national level as well. These data, which are also derived from death certificates, are provided annually via the Centers for Disease Control and Prevention's National Vital Statistics Reports. However, the variance of the life expectancy, which is necessary to perform tests of statistical significance, is not provided in the reports. We used data from 2007 to calculate the life expectancies and corresponding variances for the race/ethnic-gender groups in the USA. To calculate the number of deaths, we abstracted data from the 2007 death files obtained from the National Center for Health Statistics [34]. The number of births, as well as the population data was derived from published reports for the year 2007 [35, 36].

Two demographic variables were included in the analysis: racial/ethnic make-up and median annual household income of each community area of residence. Data on the race/ethnicspecific populations in each community area were obtained from the US Census Bureau, 2000 and 2010. Linear interpolation was used to calculate the 2006-2008 3-year average percentages for each race/ethnic group. Our analysis includes White, Black, and Hispanic race/ethnic groups. Data on median household income for each community area were obtained from the American Community Survey, 2010 (5-year estimates for 2006-2010). City-level data, derived from the same sources, are also provided for purposes of comparison.

Statistical Analysis We calculated life expectancy for each of the 77 Chicago community areas and then correlated these with the race/ethnicity and the median household income of the area. Spearman's correlation coefficients were calculated using the SAS procedure PROC CORR. $T$ tests were employed to determine whether the correlation coefficients were statistically significant. $Z$ scores were calculated to test whether the USAChicago differences in life expectancy were significant and to test whether differences between racial/ethnic groups within Chicago were significant [36]. A $p$ value of 0.05 or less was considered statistically significant for all analyses.

\section{Results}

Table 1 displays the life expectancies by race/ethnicity and gender for Chicago and the USA. The data reveal extensive variation in life expectancy across race/ethnic groups. All differences within and between race-gender groups, including USA-Chicago differences were significant at $p<0.05$, except the White USA-Chicago comparison.

The overall life expectancy for Chicago was 76.9 years. The Hispanic life expectancy was significantly higher at 84.6 years. The White life expectancy (78.8 years) was significantly lower than the Hispanic life expectancy, though still significantly higher than the Chicago average. At 71.7 years, Blacks had the lowest life expectancy, approximately 5 years lower than the overall average for the city; 13 years lower than the Hispanic life expectancy; and 7 years lower than the White life expectancy (all statistically significant).

Comparing these figures to the national data, we see that the overall life expectancy for Chicago is 1.7 years less than the national average. However, Hispanics in Chicago actually fare better than their counterparts nationally by 1.2 years. Blacks in Chicago, on the other hand, have a lower life 
Table 1 Life expectancy by race/ethnicity: USA and Chicago

\begin{tabular}{llll}
\hline & USA $^{\mathrm{a}}$ & Chicago $^{\mathrm{b}}$ & $p$ value \\
\hline Total population & 78.6 & 76.9 & $<0.00001$ \\
Male & 76.0 & 73.6 & $<0.00001$ \\
Female & 81.2 & 80.1 & $<0.00001$ \\
Black & 73.9 & 71.7 & $<0.00001$ \\
Male & 70.2 & 67.0 & $<0.00001$ \\
Female & 77.2 & 76.0 & $<0.00001$ \\
White & 78.8 & 78.8 & $\mathrm{NS}$ \\
Male & 76.2 & 75.9 & $<0.05$ \\
Female & 81.2 & 81.7 & $<0.01$ \\
Hispanic & 83.4 & 84.6 & $<0.0001$ \\
Male & 80.6 & 81.6 & $<0.0001$ \\
Female & 86.2 & 87.6 & $<0.0001$ \\
\hline
\end{tabular}

${ }^{\text {a }}$ Life expectancies are calculated from Vital Statistics record files and are for 2007 [34]

${ }^{\mathrm{b}}$ Life Expectancies are calculated from Vital Statistics record files and are 3-year averages for 2006-2008 [30]

All $Z$ tests for within-group differences were significant at the $p<0.00001$ level. This includes within-race gender differences and between-race group differences

expectancy than Blacks nationally by 2 years. Furthermore, while the Black:White difference in life expectancy is about 5 years nationally, it is 7.1 years in Chicago. Thus, large differences exist both between Chicago and the USA and between race/ethnic groups within Chicago. Additionally, among males, the Black: White gap in life expectancy is 8.9 years in Chicago compared to 6 years nationally. For females, the Black:White difference is 5.7 years in Chicago compared to 4 years nationally.

In order to further examine these race/ethnic differences, we calculated life expectancy at the community area level. Table 2 displays the life expectancies, ranked from highest to lowest, along with racial/ethnic make-up and annual household income for each of the 77 community areas in Chicago. Figure 1 displays a map of these community areas with light to dark shading for lowest to highest life expectancy. The life expectancy ranged from a low of 68.2 in West Garfield Park to a high of 83.3 in Near North Side. The community areas with the lowest life expectancies (those in the 4th quartile) were overwhelmingly located on the west and south sides of the city and had predominantly Black populations.

Table 3 displays correlation coefficients for life expectancy and racial/ethnic make-up of a community area. There was a strong, negative correlation between the proportion of Black residents in a community area and the life expectancy $(-0.75$; $p<0.0001)$. Conversely, there was a strong, positive relationship between the proportion White and life expectancy $(0.75$; $p<0.0001)$. The correlation was positive and smaller but statistically significant for Hispanic people $(0.49 ; p<0.001)$.
Table 3 also displays correlation coefficients for life expectancy and median household income. Here, we observed a strong, positive relationship between household income and life expectancy for the entire city $(0.66 ; p<0.0001)$. This relationship prevailed for the 28 community areas that were predominantly ( $60 \%$ or more) Black $(0.55 ; p<0.01)$. For the 13 predominantly White community areas, as well as the 24 community areas in which there was no majority race/ethnic group, the correlation was positive, but weak and not statistically significant. For the 12 predominantly Hispanic community areas, the relationship was negative, but weak, and not statistically significant.

\section{Discussion}

This analysis presents data on life expectancy for the USA and Chicago by race/ethnicity and gender and for Chicago's 77 community areas. Disparities are prominent. For example, in Chicago, the highest life expectancy was observed among Hispanics at 84.6 and the lowest life expectancy was observed among Blacks at 71.7-a difference of about 13 years (Table 1). Similarly, across the 77 community areas of Chicago, the life expectancy ranged from a low of 68.2 to a high of 83.3 - a difference of 15 years (Table 2). Finally, there are strong correlations between life expectancy and the racial, ethnic, and socioeconomic distributions among the community areas (Table 3).

Recent analyses of health conditions in Chicago have revealed that Blacks fare worse than Whites or Hispanics on a variety of indicators, including stroke [26], diabetes [27], and breast cancer mortality [28], as well as maternal smoking [29]. These analyses have also shown a strong, negative, and statistically significant correlation between these conditions and median household income at the community level (at the city level for breast cancer) [26-29].

There is extensive support in the literature for the relationship between socioeconomic status (SES) and poor health. Studies examining the relationship between SES and mortality at the block group, census tract, and neighborhood levels have all reported findings of substantially lower life expectancies or higher premature mortality (death before age 75) at the lowest levels of SES [18, 20, 37]. For example, a study of life expectancy among Californians in 1999-2001 found that, compared to those living in the highest SES quintile, males and females living in the lowest SES quintile had life expectancies 7 and 4.4 years lower, respectively [18]. In an analysis of premature mortality in Boston in 1999-2001, those living in the most economically deprived census tracts $(\geq 20 \%$ below poverty) had a premature mortality rate 1.39 times higher than those in the least impoverished tracts ( $<5 \%$ below poverty) [37].

There are multiple ways in which SES might impact one's health and subsequent life expectancy, and these pathways are 
Table 2 Life expectancy, race/ethnicity, and median household income for Chicago and its 77 community areas

\begin{tabular}{|c|c|c|c|c|c|}
\hline Community area $^{\mathrm{a}}$ & Life expectancy ${ }^{\mathrm{b}}$ & $\%$ White $^{\mathrm{c}}$ & $\%$ Black $^{\mathrm{c}}$ & $\%$ Hispanic $^{\mathrm{c}}$ & Household income ${ }^{\mathrm{d}}$ \\
\hline Chicago & 76.9 & 31.5 & 34.4 & 27.4 & 46,877 \\
\hline Near North Side & 83.3 & 71.3 & 13.1 & 4.6 & 77,218 \\
\hline Loop & 83.1 & 62.6 & 13.1 & 6.7 & 82,118 \\
\hline Armour Square & 83.1 & 13.6 & 12.4 & 3.5 & 29,243 \\
\hline North Park & 82.8 & 51.3 & 3.0 & 16.9 & 53,439 \\
\hline Lake View & 82.7 & 80.1 & 4.0 & 8.0 & 73,774 \\
\hline Forest Glen & 82.4 & 76.7 & 0.6 & 10.3 & 90,855 \\
\hline South Lawndale & 82.2 & 3.7 & 13.0 & 82.7 & 34,267 \\
\hline Hyde Park & 81.9 & 45.6 & 32.9 & 5.6 & 45,386 \\
\hline O'Hare & 81.5 & 78.5 & 2.9 & 8.6 & 50,948 \\
\hline Edison Park & 81.3 & 89.8 & 0.2 & 6.7 & 79,505 \\
\hline Dunning & 81.1 & 73.8 & 0.7 & 20.5 & 61,904 \\
\hline Brighton Park & 81.1 & 11.2 & 1.0 & 82.7 & 39,737 \\
\hline Lincoln Park & 80.8 & 83.4 & 4.6 & 5.4 & 85,834 \\
\hline Lower West Side & 80.8 & 11.0 & 2.6 & 84.7 & 34,005 \\
\hline Edgewater & 80.8 & 52.5 & 15.2 & 17.5 & 45,072 \\
\hline Albany Park & 80.4 & 28.7 & 3.8 & 48.5 & 46,970 \\
\hline Hermosa & 80.4 & 8.9 & 2.8 & 86.3 & 42,581 \\
\hline North Center & 80.3 & 74.7 & 2.9 & 15.6 & 82,837 \\
\hline Belmont Cragin & 80.1 & 19.0 & 3.0 & 74.8 & 43,560 \\
\hline West Elsdon & 80.1 & 25.9 & 1.1 & 70.9 & 50,140 \\
\hline West Ridge & 79.9 & 44.8 & 9.8 & 18.9 & 49,289 \\
\hline Norwood Park & 79.8 & 83.5 & 0.6 & 10.3 & 66,309 \\
\hline West Lawn & 79.8 & 22.4 & 3.7 & 72.3 & 47,595 \\
\hline Lincoln Square & 79.7 & 59.9 & 3.5 & 21.6 & 58,127 \\
\hline Portage Park & 79.7 & 58.4 & 1.1 & 34.0 & 52,102 \\
\hline Avondale & 79.7 & 28.8 & 2.2 & 63.6 & 47,223 \\
\hline Mount Greenwood & 79.7 & 87.5 & 4.7 & 6.2 & 81,885 \\
\hline Near South Side & 79.3 & 44.4 & 33.8 & 5.4 & 75,767 \\
\hline Kenwood & 79.2 & 16.3 & 73.0 & 2.6 & 40,739 \\
\hline Gage Park & 79.2 & 7.0 & 5.9 & 86.3 & 38,674 \\
\hline Jefferson Park & 79.1 & 72.6 & 0.8 & 16.9 & 61,636 \\
\hline Logan Square & 79.1 & 35.3 & 5.3 & 55.4 & 53,301 \\
\hline Beverly & 79.1 & 60.1 & 33.4 & 4.0 & 84,758 \\
\hline West Town & 79.0 & 51.4 & 8.3 & 34.8 & 64,155 \\
\hline Bridgeport & 79.0 & 36.9 & 1.8 & 28.0 & 43,142 \\
\hline Archer Heights & 78.9 & 30.7 & 0.9 & 66.6 & 44,538 \\
\hline Irving Park & 78.7 & 42.5 & 2.8 & 44.9 & 55,286 \\
\hline Montclare & 78.7 & 42.4 & 3.8 & 49.5 & 48,104 \\
\hline McKinley Park & 78.6 & 20.7 & 1.3 & 63.8 & 42,055 \\
\hline East Side & 78.1 & 20.9 & 2.7 & 75.3 & 42,109 \\
\hline Clearing & 77.7 & 58.8 & 1.0 & 38.2 & 54,571 \\
\hline Hegewisch & 77.4 & 51.7 & 3.1 & 43.2 & 49,927 \\
\hline Near West Side & 77.2 & 37.5 & 37.2 & 9.3 & 64,331 \\
\hline Ashburn & 76.5 & 21.5 & 45.3 & 31.0 & 62,311 \\
\hline Rogers Park & 76.2 & 36.8 & 27.4 & 25.5 & 40,782 \\
\hline Oakland & 76.1 & 1.6 & 95.1 & 1.3 & 21,442 \\
\hline Morgan Park & 76.0 & 29.1 & 66.7 & 2.5 & 54,507 \\
\hline Garfield Ridge & 75.8 & 58.1 & 7.9 & 32.1 & 62,694 \\
\hline
\end{tabular}


Table 2 (continued)

\begin{tabular}{|c|c|c|c|c|c|}
\hline Community area $^{\mathrm{a}}$ & Life expectancy ${ }^{\mathrm{b}}$ & $\%$ White $^{\mathrm{c}}$ & $\%$ Black $^{\mathrm{c}}$ & $\%$ Hispanic $^{\mathrm{c}}$ & Household income $^{\mathrm{d}}$ \\
\hline Avalon Park & 75.6 & 0.8 & 96.2 & 1.3 & 44,568 \\
\hline Uptown & 75.3 & 48.5 & 20.4 & 16.1 & 40,874 \\
\hline Chicago Lawn & 75.2 & 6.2 & 50.3 & 41.9 & 39,437 \\
\hline Woodlawn & 74.9 & 5.4 & 89.4 & 1.8 & 28,757 \\
\hline Chatham & 74.5 & 0.3 & 97.5 & 0.9 & 33,812 \\
\hline Calumet Heights & 74.2 & 1.0 & 93.2 & 4.3 & 56,160 \\
\hline New City & 73.9 & 11.4 & 31.5 & 54.9 & 35,169 \\
\hline Humboldt Park & 73.8 & 4.1 & 43.1 & 51.6 & 30,152 \\
\hline South Deering & 73.8 & 5.7 & 61.6 & 31.4 & 38,374 \\
\hline South Chicago & 73.5 & 2.3 & 72.4 & 23.7 & 32,812 \\
\hline Pullman & 73.2 & 7.6 & 82.8 & 8.2 & 37,392 \\
\hline Grand Boulevard & 72.7 & 1.4 & 95.4 & 1.5 & 31,220 \\
\hline Burnside & 72.6 & 0.8 & 97.3 & 0.8 & 31,391 \\
\hline Auburn Gresham & 72.6 & 0.3 & 97.9 & 0.8 & 35,120 \\
\hline Austin & 72.0 & 4.6 & 86.6 & 7.3 & 34,366 \\
\hline Washington Heights & 71.7 & 0.5 & 97.4 & 0.9 & 43,158 \\
\hline Roseland & 71.5 & 0.5 & 97.5 & 0.9 & 40,462 \\
\hline Riverdale & 71.5 & 0.6 & 96.5 & 1.9 & 13,734 \\
\hline South Shore & 71.2 & 1.2 & 95.5 & 1.5 & 28,264 \\
\hline North Lawndale & 70.9 & 1.2 & 92.2 & 5.5 & 27,024 \\
\hline West Pullman & 70.6 & 0.7 & 93.2 & 4.9 & 39,078 \\
\hline Greater Grand Crossing & 70.6 & 0.5 & 97.2 & 1.0 & 30,183 \\
\hline West Englewood & 70.4 & 0.4 & 96.8 & 1.8 & 27,174 \\
\hline Douglas & 70.2 & 8.6 & 77.6 & 2.0 & 35,743 \\
\hline East Garfield Park & 70.0 & 2.7 & 92.8 & 3.2 & 25,568 \\
\hline Englewood & 69.5 & 0.4 & 97.5 & 1.0 & 20,813 \\
\hline Fuller Park & 68.4 & 1.3 & 92.9 & 4.2 & 16,107 \\
\hline Washington Park & 68.3 & 0.7 & 97.2 & 0.9 & 23,090 \\
\hline West Garfield Park & 68.2 & 0.7 & 96.8 & 1.6 & 23,933 \\
\hline
\end{tabular}

${ }^{a}$ See Fig. 1 for a map of Chicago's 77 community areas

${ }^{\mathrm{b}}$ Life expectancies are calculated from Vital Statistics record files and are 3-year averages for 2006-2008 [30]

${ }^{\mathrm{c}}$ Race/ethnicity percentages are 3-year averages for 2006-2008, based on linear interpolation of 2000 and 2010 US Census Bureau data

${ }^{\mathrm{d}}$ Household income is based on the American Community Survey, 2006-2010, 5-year estimates

described extensively in the literature. For example, it is generally understood that living in poverty may impede one's ability to acquire knowledge about, locate, or obtain access to health-promoting and illness-preventing resources. Thus, residents of poor neighborhoods may experience fewer opportunities to engage in physical activity, buy healthy foods, or access quality health care. The strain of living with limited resources can produce stress and anxiety, which can impact health either directly, through the weathering effect, or indirectly, through the uptake of unhealthy behaviors like smoking, drinking, and drug use. Cultural norms, which may vary by income, can also play a role in behavioral choices like smoking and diet $[18,20]$.
Although SES is clearly an important factor in understanding racial disparities in health, it alone cannot fully account for the observed differences. Recent studies have reported disparities in mortality among Blacks and Whites even after adjusting for SES [18, 38]. For example, in their study of life expectancy in California, Clarke et al. observed a 2-4 year gap in life expectancy between Blacks and Whites across all levels of neighborhood SES [18]. There are several pathways through which race may impact health outcomes, including segregation and discrimination, both of which are the result of racism [39]. Segregation results in unequal exposure to social and environmental risks and unequal access to healthpromoting resources, all of which impact health $[14,39]$. 
Fig. 1 Life expectancy by Chicago community area

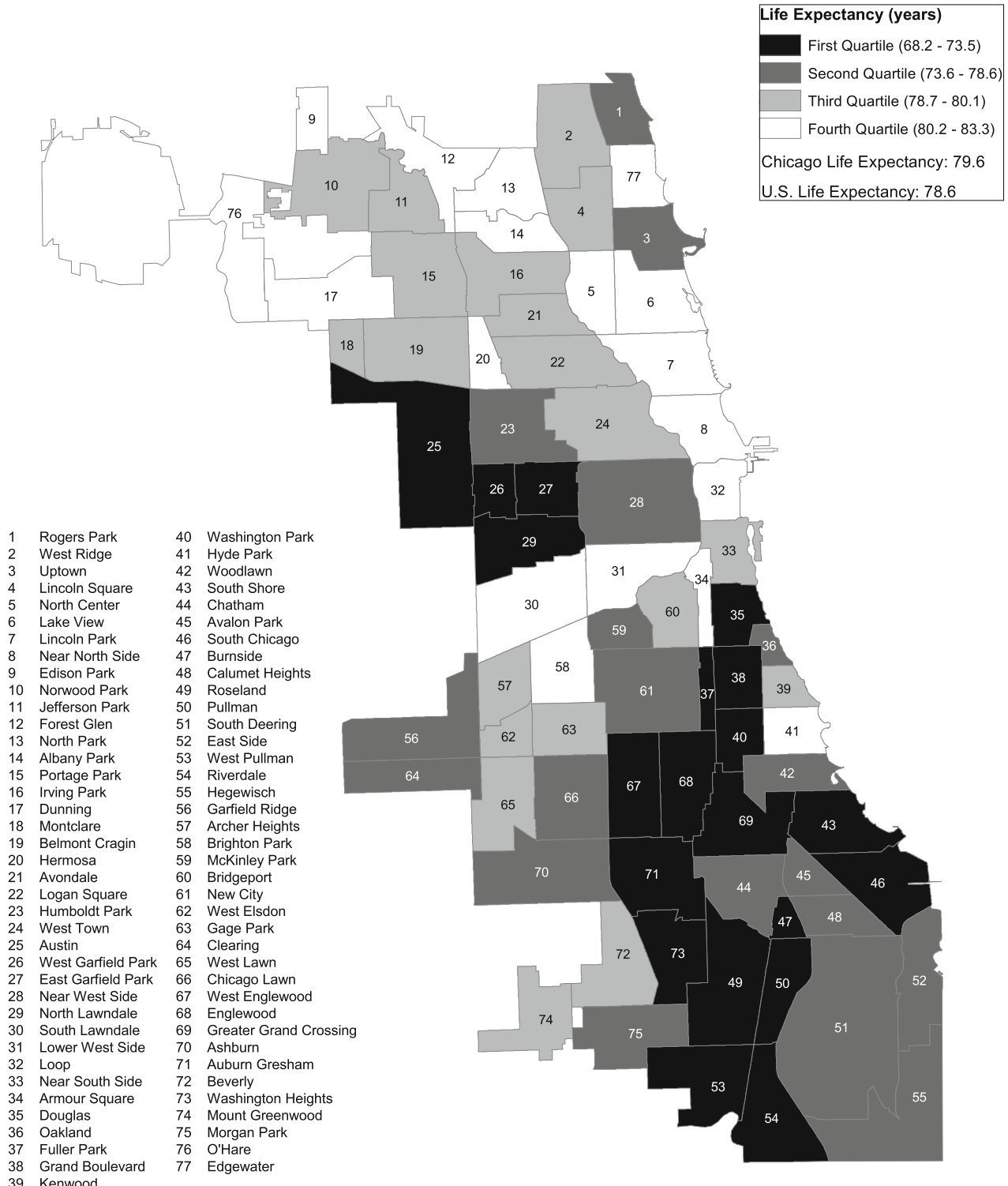

Perceived discrimination significantly and negatively affects both mental and physical health outcomes [40]. Moreover, it can indirectly affect health outcomes via mediating mechanisms such as increased stress responses and altered health behaviors [40].

When discussing the effect of race and SES on health outcomes like life expectancy, it is informative to consider the finding of relatively long life expectancy among US Hispanics, who outlive both White and Black Americans, despite having an SES profile comparable to that of Blacks and worse than that of Whites. This apparent paradox, often referred to as the "Hispanic Paradox", has been widely discussed, and several theories have been put forth to explain it.

Two theories, both having to do with migration patterns, have found some support in the literature. The "salmon bias" suggests that the return to the home country among ill immigrants artificially deflates the death rate among Hispanics in the USA, resulting in the appearance of a longer life expectancy [41-43]. The other migration-based theory points to a selection effect, whereby Hispanics migrating to the USA tend to be healthier than their counterparts who stay behind. Research suggests that the selection effect may play more of a role than return migration in the apparently longer life expectancy of Hispanics [43].

One health behavior thought to explain Hispanics' longer life expectancy is their lower tobacco use - the share of Hispanics who smoke at all is small and those who do smoke, smoke fewer cigarettes [44]. In a recent study of Americans ages 50 and older, when researchers eliminated smokers from the analysis, they observed that life expectancy among foreign-born Hispanics did not significantly exceed that for non-Hispanic Whites, and US-born Hispanics' life expectancy 
Table 3 Correlation of life expectancy ${ }^{\mathrm{a}}$ with race/ethnicity ${ }^{\mathrm{b}}$ and median household income ${ }^{\mathrm{c}}$

\begin{tabular}{lll}
\hline & $\mathrm{R}$ & $p$ value \\
\hline $\begin{array}{l}\text { Proportion of community area } \\
\quad \text { Black }\end{array}$ & -0.75 & $<0.0001$ \\
$\quad$ White & 0.75 & $<0.0001$ \\
$\quad$ Hispanic & 0.49 & $<0.001$ \\
Median household income & & \\
$\quad$ City of Chicago & 0.66 & $<0.0001$ \\
$\quad$ Predominant race/ethnic population ${ }^{\mathrm{d}}$ & & \\
$\quad$ Black $(N=28)$ & 0.55 & $<0.01$ \\
$\quad$ White $(N=13)$ & 0.01 & 0.98 \\
$\quad$ Hispanic $(N=12)$ & -0.32 & 0.32 \\
$\quad$ Other or no majority $(N=24)$ & 0.13 & 0.56 \\
\hline
\end{tabular}

${ }^{\mathrm{a}}$ Life expectancies are calculated from Vital Statistics record files and are 3-year averages for 2006-2008 [30]

${ }^{\mathrm{b}}$ Race/ethnicity proportions are 3-year averages for 2006-2008, based on linear interpolation of 2000 and 2010 US Census Bureau data

${ }^{\mathrm{c}}$ Household income is based on the American Community Survey, 20062010, 5-year estimates

${ }^{\mathrm{d}}$ Refers to community areas in which $60 \%$ or more of the population is of the specified race/ethnicity

dropped below that for non-Hispanic Whites [45]. However, despite being less likely to smoke and drink, foreign-born Hispanics 50 and older are equally likely to be obese and they exercise about the same amount (not very much) as their nonHispanic White counterparts [45].

Cultural differences have also been cited to explain this paradox. One explanation of this type is the "barrio advantage," which posits that Mexican Americans living in predominantly Mexican neighborhoods have some protective cultural advantage that outweighs the disadvantages of poverty. A 2004 study found support for this notion, noting that older Mexican Americans benefited from immersion in special sociocultural environments which provide a buffer against many of the unhealthful aspects of US culture, but facilitate social support from kinship and community, resulting in lower morbidity and mortality. Indeed, the authors report a significant linear trend for increased neighborhood percentage Mexican American and lower disease prevalence of many medical conditions [46].

\section{Methodological Considerations}

The analysis presented in this paper is subject to at least two statistical problems. First, to avoid an ecological fallacy, we acknowledge that the relationships observed at the community level will not necessarily apply to every individual within that community. Second, the correlation analysis is subject to the modifiable areal unit problem, given that point-based estimates have been aggregated to the community area level, but that the community area boundaries are arbitrarily drawn and modifiable. A re-drawing of these boundaries and corresponding re-grouping of data could produce radically different results.

The primary goal of the present analysis was to demonstrate the importance of local-level data in revealing those areas in greatest need and guiding resource allocation. We were less concerned with presenting an exhaustive analysis of the predictors of variation in life expectancy. We therefore acknowledge that the present analysis could be expanded to include any number of variables thought to impact life expectancy, and we encourage such analyses in future research, particularly as they contribute to the overall understanding of why certain areas see better/worse health outcomes than others.

\section{Conclusion}

Public awareness of racial disparities in health has the potential to influence the response of policymakers, individuals, and communities. Similarly, lack of awareness can result in lack of attention to the problem and action to address it [47]. Thus, the importance of studies like the present one and those referenced throughout this discussion cannot be overstated. The examination of data at the local level provides invaluable insight into which communities are facing the greatest burden in terms of health and well-being. It is only through the examination of local-level data that we can understand the unique needs of these communities and begin to address them. For example, when our previous work revealed a high prevalence of and mortality from diabetes in one particular Chicago community, this led to the development and implementation of a diabetes intervention, the founding of a community-based organization focused on diabetes, and a National Institutes of Health grant to support this work [48]. Thus, this type of data is critical both for catalyzing community action and securing funding to support health interventions.

Conflict of Interest Author Bijou Hunt, Author Gary Tran, and Author Steve Whitman declare that they have no conflict of interest.

Animal Studies No animal or human studies were carried out by the authors for this article.

\section{References}

1. National Center for Health Statistics. Health United States 2012. With Special Feature on Emergency Care. Hyattsville, MD. 2013.

2. Levine RS, Foster JE, Fullilove RE, Fullilove MT, Briggs NC, Hull $\mathrm{PC}$, et al. Black-white inequalities in mortality and life expectancy, 
1933-1999: implications for healthy people 2010. Public Health Rep. 2001;116(5):474-83.

3. Harper S, Lynch J, Burris S, Davey Smith G. Trends in the blackwhite life expectancy gap in the United States, 1983-2003. JAMA. 2007;297(11):1224-32.

4. Ho JY. Mortality under age 50 accounts for much of the fact that US life expectancy lags that of other high-income countries. Health Aff. 2013;32(3):459-67.

5. Pinkhasov RM, Shteynshlyuger A, Hakimian P, Lindsay GK, Samadi DB, Shabsigh R. Are men shortchanged on health? Perspective on life expectancy, morbidity, and mortality in men and women in the United States. Int J Clin Pract. 2010;64(4):465-74.

6. Olshansky SJ, Antonucci T, Berkman L, Binstock RH, BoerschSupan A, Cacioppo JT, et al. Differences in life expectancy due to race and educational differences are widening, and many may not catch up. Health Aff. 2012;31(8):1803-13.

7. Meara ER, Richards S, Cutler DM. The gap gets bigger: changes in mortality and life expectancy, by education, 1981-2000. Health Aff. 2008;27(2):350-60.

8. Wilkinson RG, Pickett KE. Income inequality and socioeconomic gradients in mortality. Am J Public Health. 2008;98(4):699-704.

9. Singh GK, Siahpush M. Widening socioeconomic inequalities in US life expectancy, 1980-2000. Int J Epidemiol. 2006;35(4):969-79.

10. Phelan JC, Link BG, Diez-Roux A, Kawachi I, Levin B. "Fundamental causes" of social inequalities in mortality: a test of the theory. J Health Soc Behav. 2004;45(3):265-85.

11. Gee GC, Walsemann KM, Brondolo E. A life course perspective on how racism may be related to health inequities. Am J Public Health. 2012;102(5):967-74.

12. Hatzenbuehler ML, Phelan JC, Link BG. Stigma as a fundamental cause of population health inequalities. Am J Public Health. 2013;103(5):813-21.

13. Collins CA. Racism and health: segregation and causes of death amenable to medical intervention in major U.S. Cities. Ann N Y Acad Sci. 1999;896:396-8.

14. LaVeist TA. Racial segregation and longevity among African Americans: an individual-level analysis. Health Serv Res. 2003;38(6 Pt 2):1719-34.

15. Arias E, United States Life Tables, 2009. National vital statistics reports; vol 62 no 7. Hyattsville: National Center for Health Statistics; 2014.

16. Lewis K, Burd-Sharps S. The measure of America 2013-2014. Available at: http://ssrc-static.s3.amazonaws.com/moa/MOA-IIIJune-18-FINAL.pdf. Accessed on July 12014.

17. Bharmal N, Tseng CH, Kaplan R, Wong MD. State-level variations in racial disparities in life expectancy. Health Serv Res. 2012;47(1 Pt 2):544-55

18. Clarke CA, Miller T, Chang ET, Yin D, Cockburn M, Gomez SL. Racial and social class gradients in life expectancy in contemporary California. Soc Sci Med. 2010;70(9):1373-80.

19. Redelings M, Lieb L, Sorvillo F. Years off your life? The effects of homicide on life expectancy by neighborhood and race/ethnicity in Los Angeles County. J Urban Health. 2010;87(4):670-6.

20. Myers C, Olson C, Kerker B, Thorpe L, Greene C, Farley T. Reducing health disparities in New York City: health disparities in life expectancy and death. New York: New York City Department of Health and Mental Hygiene; 2010.

21. Wilson M, Daly M. Life expectancy, economic inequality, homicide, and reproductive timing in Chicago neighbourhoods. BMJ. 1997;314(7089):1271-4.

22. Kulkarni SC, Levin-Rector A, Ezzati M, Murray CJ. Falling behind: life expectancy in US counties from 2000 to 2007 in an international context. Popul Health Metrics. 2011;9(1):16.

23. Whitman S, Shah AM, Benjamins MR, editors. Urban health: combating disparities with local data. New York: Oxford University Press; 2010.
24. Glaeser E, Vigdor JL. The end of the segregated century: racial separation in America's Neighborhoods, 1890-2010. Manhattan Institute. Civic Report 66, January 2012.

25. Hunt BR, Whitman S. Black-white health disparities in the United States and Chicago: 1990-2010. J Racial Ethnic Health Disparities. 2014. doi:10.1007/s40615-014-0052-0.

26. Hunt BR, Deot D, Whitman S. Stroke mortality rates vary in local communities in a metropolitan area: racial and spatial disparities and correlates. Stroke. 2014;45:2059-65.

27. Hunt BR, Whitman S, Henry C. Age-adjusted diabetes mortality rates vary in local communities in a metropolitan area: racial and spatial disparities and correlates. Diabetes Care. 2014. doi:10.2337/dc130988.

28. Whitman S, Orsi J, Hurlbert M. The racial disparity in breast cancer mortality in the 25 largest cities in the United States. Cancer Epidemiol. 2012;36(2):e147-51.

29. Hunt BR, Whitman S. Maternal smoking in Chicago: a communitylevel analysis. J Health Care Poor Underserved. 2011;22:194-210.

30. These data were derived by the Chicago Department of Public Health from a record set supplied by the Illinois Department of Public Health (IDPH). IDPH specifically disclaims responsibility for any analysis, interpretations, or conclusions.

31. Chiang CL. Introduction to stochastic processes in biostatistics. New York: Wiley; 1968.

32. Preston S, Keyfitz J, Schoen R. Causes of death: life tables for national populations. New York: Seminar Press; 1971.

33. Approval from the Institutional Review Board was not necessary as the data are de-identified, public-use data.

34. National Center for Health Statistics. Mortality - All County (microdata) (2007), as compiled from data provided by the 57 vital statistics jurisdictions through the Vital Statistics Cooperative Program.

35. Arias E, United States Life Tables, 2007. National vital statistics reports; 59(9). Hyattsville: National Center for Health Statistics; 2011.

36. Xu JQ, Kochanek KD, Murphy SL, Tejada-Vera B. Deaths: final data for 2007. National vital statistics reports; vol 58 no 19. Hyattsville: National Center for Health Statistics; 2010.

37. Chen JT, Rehkopf DH, Waterman PD, Subramanian SV, Coull BA, Cohen B, et al. Mapping and measuring social disparities in premature mortality: the impact of census tract poverty within and across Boston Neighborhoods, 1999-2001. J Urban Health Bull N Y Acad Med. 2006;83(6):1063-84.

38. Lin CC, Rogot E, Johnson NJ, Sorlie PD, Arias E. A further study of life expectancy by socioeconomic factors in the national longitudinal mortality study. Ethn Dis. 2003;13(2):240-7.

39. Williams DR, Mohammed SA. Racism and health I: pathways and scientific evidence. Am Behav Sci. 2013;57(8):1152-73.

40. Pascoe EA, Richman LS. Perceived discrimination and health: a meta-analytic review. Psychol Bull. 2009;135(4):531-54.

41. Palloni A, Arias E. Paradox lost: explaining the adult Hispanic mortality advantage. Demography. 2004;41(3):385-415.

42. Turra C, Irma E. The impact of Salmon Bias on the Hispanic mortality advantage: new evidence from social security data. Popul Res Policy Rev. 2008;27(5):515-30.

43. Riosmena F, Wong R, Palloni A. Migration selection, protection, and acculturation in health: a binational perspective on older adults. Demography. 2012; article ID 1533-7790 (online).

44. Blue L, Fenelon A. Explaining low mortality among U.S. immigrants relative to native-born Americans: the role of smoking. Int $\mathrm{J}$ Epidemiol. 2011;40(3):786-93.

45. Hayward $\mathrm{M}$ et al. "Does the hispanic paradox in mortality extend to disability?" paper presented at the MacArthur foundation research network on an aging society, Palo Alto, CA, 2011.

46. Eschbach K, Ostir GV, Patel KV, Markides KS, Goodwin JS. Neighborhood context and mortality among older Mexican 
Americans: is there a barrio advantage? Am J Public Health. 2004;94:1807-12.

47. Benz JK, Espinosa O, Welsh V, Fontes A. Awareness of racial and ethnic health disparities has improved only modestly over a decade. Health Aff. 2011;30(10):1860-7.
48. Whitman S, Lopez JE, Rothschild SK, Delgado J. Disproportionate impact of diabetes in a Puerto Rican community of Chicago. In: Whitman S, Shah A, Benjamins M, editors. Urban health: combating disparities with local data. New York: Oxford University Press; 2010. p. 225-46. 